\title{
Discussion on reaction mechanism of enoxacine-terbium complex
}

\author{
Weiwei Bian \\ Medical Chemistry Staff Room, \\ Weifang Medical University,Weifang, Shandong, PR China
}

Keywords: reaction, mechanism, complex.

\begin{abstract}
In the buffer solution of $\mathrm{pH}=5.80$, bilirubin can remarkably reduce the fluorescence intensity of the enoxacine - terbium $\left(\mathrm{Tb}^{3+}\right)$ complex at $\lambda=545 \mathrm{~nm}$ and the reduced fluorescence intensity of $\mathrm{Tb}^{3+}$ ion is in proportion to the concentration of bilirubin. The influential factors were investigated. The reducement mechanism of the fluorescence intensity in the enoxacine $-\mathrm{Tb}^{3+}$ and the enoxacine $-\mathrm{Tb}^{3+}$-bilirubin complex have been discussed. In this experiment, the results showed the binding force between enoxacine and bilirubin was stronger than that of enoxacine and $\mathrm{Tb}^{3+}$, bilirubin can join with enoxacine more easily than $\mathrm{Tb}^{3+}$. Therefore, the enoxacine joined with $\mathrm{Tb}^{3+}$ was fewer, the fluorescence intensity of $\mathrm{Tb}^{3+}$ at $545 \mathrm{~nm}$ reduced.
\end{abstract}

\section{Introduction}

Bilirubin (BR) is the end product of heme metabolihumans [1]. BR level in newborns is typically 10 times higher than that of adults. A low bilirubin level may indicate an iron deficiency [3]. So the BR analysis is believed to have considerable medicinal properties.Now the most commonly used methods for bilirubin analysis include capillary electrophoresis[4], diazo reaction [3] , high-performance liquid chromatography[4], fiber optic sensor[5], fluoroimmunoassay[6], flow injection[7], spectrophotometer[8-11], But there is no report about spectrofluorimetric method for determination of $\mathrm{BR}$ using ENX-Tb3+ as a fluorescent probe and the mechanism of the fluorescence intensity in the enoxacine -Tb3+ and the enoxacine -Tb3+-bilirubin complex. Enoxacine (ENX) is one kind of bacteriophages containing $\alpha$-carbonyl carboxylic acid configuration. It is the ideal ligand for Tb3+. In this work, we chose ENX as the ligand of Tb3+ and investigated the possibility of the reducement of the Tb3+ fluorescence sensitized by it and using $\mathrm{BR}$ as co-ligand. Experimental results show that the characteristic peak of Tb3+ at $545 \mathrm{~nm}$ can be greatly reduced and the reduced fluorescence intensity is proportional to the concentration of BR. Under the optimum condition, the mechanism of fluorescence reducement between Tb3+-ENX complexes and BR was studied.

\section{Experimental}

\subsection{Reagents}

All chemicals used were of analytical-reagent or higher grade. Doubly distilled demineralized water was used for the preparation of all solutions and for all determinations.

A stock bilirubin (BR,Weihui Biochemical Co., shanghai) was dissolved with a small amount of $0.1 \mathrm{~mol} \mathrm{~L}-1 \mathrm{NaOH}$, then diluting to mark with doubly distilled demineralized water and working standard solution (1.0×10-4 mol L-1) was freshly prepared by appropriate dilution with doubly distilled demineralized water. A Tb3+ ion stock solution was prepared by dissolving Tb4O7 (more than 99.99\%, Shanghai Yuelong Chemical Plant, China) with a small amount of hydrochloric acid, then diluting to mark with hydrochloric acid $(0.1 \mathrm{~mol} / \mathrm{L})$. The working solution $(5.0 \times 10-5 \mathrm{~mol} / \mathrm{L})$ was obtained by appropriate dilution the stocked solution with doubly distilled demineralized water. Stock enoxacine (ENX, Biological Product Institution of Chinese Medicine) solution was directly dissolved in doubly distilled demineralized water. The working standard solution $(8.8 \times 10-4 \mathrm{~mol} / \mathrm{L})$ was freshly prepared by appropriate dilution with doubly distilled demineralized water.0.10 mol L-1 NH4AC-HAC $(\mathrm{pH}=5.80)$ buffer solution. 


\subsection{Apparatus}

All fluorescence measurements were carried out on a RF-540 recording spectrofluorimeter (Shimadzu, Kyoto, Japan). A UV-265 recording spectrophotometer (Shimadzu, Kyoto, Japan) was used for UV spectra scanning and the determination experiments. All $\mathrm{pH}$ measurements were made with a pHs-3C digital pH meter (Shanghai Leici Device works,China).

\subsection{Experiment procedure}

According to the experiment results, the optimum condition is that: to $10 \mathrm{ml}$ color comparison tubes, solutions were added in the following order: $1.5 \mathrm{~mL} \mathrm{pH=5.80} 0.10 \mathrm{~mol} \mathrm{~L}-1 \mathrm{NH} 4 \mathrm{AC}-\mathrm{HAC}$ buffer solution, $1.5 \mathrm{~mL} 8.8 \times 10-6 \mathrm{~mol} \mathrm{~L}-1 \mathrm{ENX}, 1.5 \mathrm{~mL} 5.0 \times 10-4 \mathrm{~mol} / \mathrm{L} \mathrm{Tb}+$ and $0.5 \mathrm{~mL} 1.0 \times 10-4$ mol L-1 BR. The mixture was diluted to $10 \mathrm{ml}$ with deionized distilled water and stand for $15 \mathrm{~min}$ at room temperature. The fluorescence intensity was measured at $\lambda$ ex $/ \lambda \mathrm{em}=335 \mathrm{~nm} / 545 \mathrm{~nm}$. The decreased fluorescence intensity of ENX-Tb3+ by BR was represented as $\Delta \mathrm{F}=\mathrm{F} 0-\mathrm{F}$. Here $\mathrm{F}$ and $\mathrm{F} 0$ are the intensities of the systems with and without BR, respectively.

\section{Results and discussion}

\subsection{Apparatus}

Fluorescence Spectra. Fluorescence spectra of ENX, Tb3+, BR, ENX-Tb3+, ENX-BR, Tb3+-BR and ENX-Tb3+-BR are shown in the Fig.1. It is known that it is hardly to excite the characteristic peak of Tb3+, and the peak is also unclear in the system of BR- Tb3+. But at the same condition, characteristic peak of ENX-Tb3+ is observed and the two emission peaks are at 490nm and 545nm, which correspond to the 5D0-7F1 and 5D0-7F2 transitions of Tb3+ respectively. The fluorescence spectra of ENX- Tb3+-BR system is similar to that of ENX- Tb3+, but the fluorescence intensity of ENX- Tb3+ is decreased by BR, and the decreased fluorescence intensity is proportional to the concentration of BR.

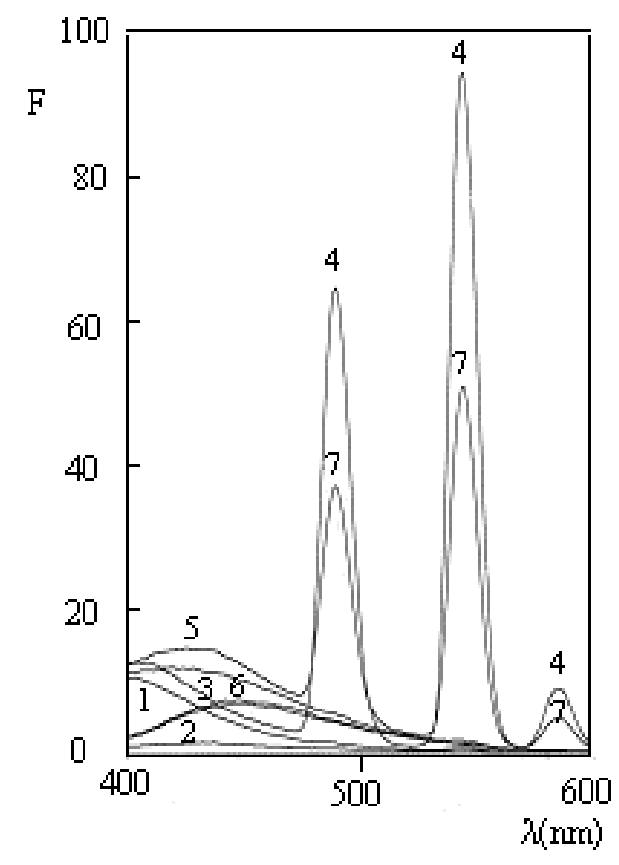

Fig.1 Fluorescence spectra

\subsection{Effect of the addition order of reagents.}

Adding various reagents in different order had an influence on the $F, F 0$ and $\Delta F$. The experimental results are shown in Table 1. Considering both the enhancement of fluorescence intensity and the stability of BR, No.1 was optimum. 


\subsection{Influence of Coexisting Substance.}

Series experiments of coexist substance had been carried out on the fluorescence of ENX-Tb3+-BR comlex under the optimum condition. Including mental ions, bases and proteins were also examined for interference. Results are summarized in Table 2. Most of them do not interfere when BR is $2.0 \times 10-5 \mathrm{~mol} \mathrm{L-1.}$

Table 1.Impact of the order of addition of reagents on the fluorescence intensity

\begin{tabular}{clccc}
\hline NO & Addition order of reagent & $\mathrm{F}_{0}$ & $\mathrm{~F}$ & $\Delta \mathrm{F}$ \\
\hline 1 & buffer, ENX, $\mathrm{Tb}^{3+}, \mathrm{BR}$ & 59.1 & 33.8 & 25.3 \\
2 & $\mathrm{ENX}^{3} \mathrm{~Tb}^{3+}, \mathrm{BR}$, buffer & 58.7 & 34.6 & 24.1 \\
3 & $\mathrm{ENX}, \mathrm{BR}, \mathrm{Tb}^{3+}$, buffer & 58.7 & 33.6 & 25.1 \\
5 & $\mathrm{BR}, \mathrm{buffer}, \mathrm{ENX}, \mathrm{Tb}^{3+}$ & 59.1 & 33.1 & 26.0 \\
6 & buffer, BR, $\mathrm{Tb}^{3+}, \mathrm{ENX}$ & 61.3 & 35.6 & 25.7 \\
7 & $\mathrm{BR}^{3+} \mathrm{Tb}^{3+}, \mathrm{ENX}, \mathrm{buffer}$ & 58.6 & 34.6 & $24 . .0$ \\
8 & $\mathrm{~Tb}^{3+}, \mathrm{buffer}, \mathrm{BR}, \mathrm{ENX}$ & 58.3 & 33.7 & 24.6 \\
\hline
\end{tabular}

Table 2. Influence of coexisting substance on ENX- $\mathrm{Tb}^{3+}$-BR comlex

\begin{tabular}{ccc}
\hline $\begin{array}{c}\text { Coexisting } \\
\text { substance }\end{array}$ & $\begin{array}{c}\text { concentration }(\mathrm{mol} \\
\left.\mathrm{L}^{-1}\right)\end{array}$ & $\Delta \mathrm{F} \%$ \\
\hline $\mathrm{Co}^{2+}$ & $5.0 \times 10^{-5}$ & -8.20 \\
$\mathrm{Cu}^{2+}$ & $2.5 \times 10^{-7}$ & -1.16 \\
$\mathrm{Mg}^{2+}$ & $5.0 \times 10^{-4}$ & -0.61 \\
$\mathrm{Fe}^{3+}$ & $1.8 \times 10^{-7}$ & 2.12 \\
$\mathrm{Hg}^{2+}$ & $2.5 \times 10^{-8}$ & 4.76 \\
$\mathrm{Cd}^{2+}$ & $1.8 \times 10^{-6}$ & -8.30 \\
$\mathrm{Al}^{3+}$ & $1.9 \times 10^{-6}$ & -0.70 \\
$\mathrm{Ca}^{2+}$ & $1.0 \times 10^{-4}$ & -7.36 \\
$\mathrm{Zn}^{2+}$ & $2.4 \times 10^{-4}$ & -5.37 \\
$\mathrm{Mn}^{2+}$ & $2.5 \times 10^{-4}$ & -8.3 \\
$\mathrm{Cr}^{3+}$ & $3.8 \times 10^{-6}$ & -1.16 \\
$\mathrm{Mo}^{6+}$ & $1.0 \times 10^{-6}$ & -7.90 \\
$\mathrm{~Tb}^{3+}$ & $2.0 \times 10^{-6}$ & -2.58 \\
\hline
\end{tabular}




\begin{tabular}{clc}
\hline $\mathrm{K}^{+}$ & $2.1 \times 10^{-4}$ & -0.58 \\
$\mathrm{Na}^{+}$ & $2.2 \times 10^{-4}$ & 2.12 \\
$\mathrm{HSA}$ & $9.3 \times 10^{-6}$ & -8.47 \\
$\mathrm{C}_{2} \mathrm{O}_{4}{ }^{2-}$ & $1.3 \times 10^{-6}$ & 2.39 \\
$\mathrm{Sr}^{2+}$ & $1.0 \times 10^{-7}$ & -0.79 \\
thymine & $1.8 \times 10^{-6}$ & -1.48 \\
cytosine & $1.1 \times 10^{-4}$ & -0.55 \\
guanine & $1.6 \times 10^{-7}$ & -0.59 \\
adenine & $1.0 \times 10^{-8}$ & 0.93 \\
acetocaustin & $2.0 \times 10^{-4}$ & 0.39 \\
cane sugar & $1.0 \times 10^{-3}$ & -1.78 \\
histidine & $9.8 \times 10^{-5}$ & -7.59 \\
lysine & $2.0 \times 10^{-4}$ & -9.00 \\
glucose & $1.0 \times 10^{-4}$ & -4.44 \\
methionine & $2.0 \times 10^{-4}$ & 1.66 \\
glutamic & $4.0 \times 10^{-5}$ & 4.24 \\
cystine & $1.0 \times 10^{-5}$ & 1.11 \\
tryptophine & $5.0 \times 10^{-4}$ & 3.56 \\
& $1.0 \times 10^{-4}$ & 1.30 \\
glycine & $1.0 \times 10^{-3}$ & -1.29 \\
\hline
\end{tabular}

\subsection{Reaction mechanism}

Enoxacine is one kind of bacteriophages containing $\alpha$-carbonyl carboxylic acid configuration. Literature survey showed that $\alpha$-carbonyl ligands were suitable for efficient energy transfer from ligands to Tb3+ and for high fluorescence quantum yield; large stokes shift; narrow emission bonds; a large fluorescence lifetime and hence avoid potential background fluorescent emission interferences from the biological background. Therefore, ENX was ideal ligand for Tb3+ and it can possibly sensitize the fluorescence intensity of Tb3+ via intramolecular energy transfer [10].

In this experiment, the results showed that the characteristic peak of Tb3+ at $545 \mathrm{~nm}$ can be greatly reduced by BR and the reduced fluorescence intensity is proportional to the concentration of $\mathrm{BR}$. It was assumed that the binding force between ENX and BR was stronger than that of ENX and Tb3+, BR can join with ENX more easily than Tb3+. Therefore, the ENX joined with Tb3+ was fewer, the fluorescence intensity of Tb3+ at 545nm reduced.

Next we proved the theory with formation constant. BR can form a complex with ENX, the procedure was dynamic quenching. 
Quenching equation [11]:

$1 /\left(\mathrm{F}_{0}-\mathrm{F}\right)=1 / \mathrm{F}_{0}+\mathrm{K}_{\mathrm{D}} /\left(\mathrm{F}_{0}[\mathrm{Q}]\right)$

In the equation, [Q] is the concentration of BR. The plot of $1 /(\mathrm{F} 0-\mathrm{F})$ vs $1 /[\mathrm{Q}]$ was showed in figure 2. Figure 2 shows that curves have fine linear relationships. This indicates the static quenching interaction between ENX and BR. The formation constant KA can be obtained from the Fig.2 $(\mathrm{KA}=1 / \mathrm{KD})$. When $\mathrm{t}=25.0^{\circ} \mathrm{C}$, regression equation is $\mathrm{Y}=-0.01153+3.98423 \times 10-7$, $\mathrm{KA}=3.0240 \times 104, \mathrm{r}=0.99823$ 。

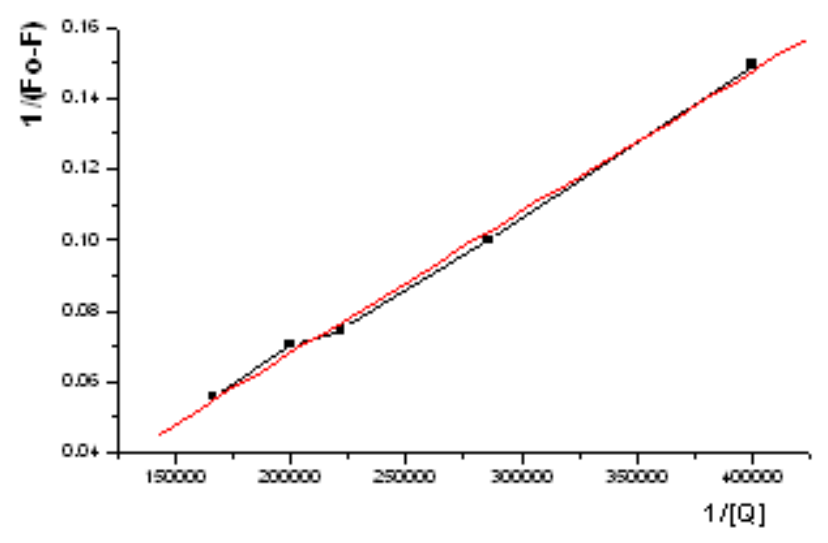

Figure 2

We got the formation constant of ENX and Tb3+ with the same method. It was showed in figure 3. When $\mathrm{t}=25.0^{\circ} \mathrm{C}$, regression equation is $\mathrm{Y}=-0.00663+1.03927 \times 10-6, \mathrm{KA}=1.1085 \times 104$, $\mathrm{r}=0.99745$.

In conclusion, the formation constant of ENX and BR was bigger than that of ENX and Tb3+, which indicated that the binding force between ENX and BR was stronger than that of ENX and Tb3+, BR can join with ENX more easily than Tb3+. The ENX joined with Tb3+ was fewer, so the fluorescence intensity of Tb3+ at 545nm reduced. It was ideal proof for the theory above.

Otherwise, according to Förster dipole-dipole nonradiative energy transfer theory [10], there will be nonradiative energy transfer phenomenon when two compound molecules satisfy the conditions below: (1) the energy donor(d) can emits fluorescence; (2) the energy donor's fluorescence emission spectrum have enough overlap with the absorption spectrum of the energy acceptor(a). (3) the energy donor and the energy acceptor must be near enough and the maximum distance of $\mathrm{d}-\mathrm{a}$ is $7 \mathrm{~nm}$.

The overlap of the fluorescence emission spectra of ENX (a) with the absorption spectra (b) of BR is shown in figure 4, which indacated there was energy transfer between ENX and BR. Figure 4 provided ideal proof for the theory above.

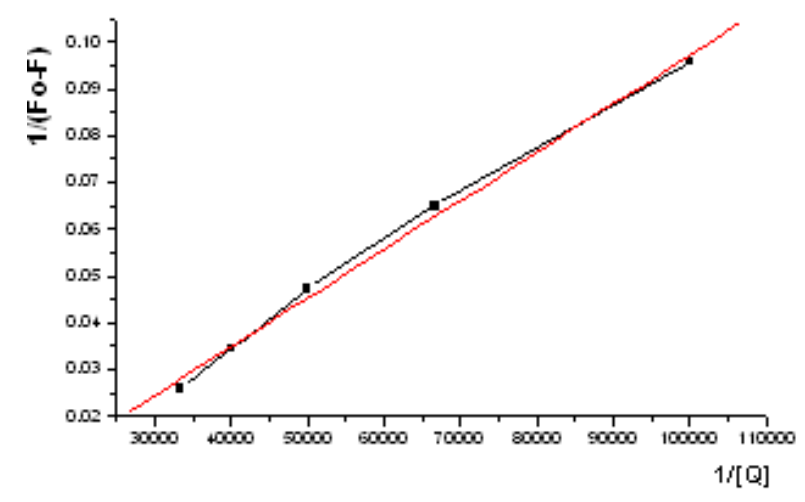

Figure 3 


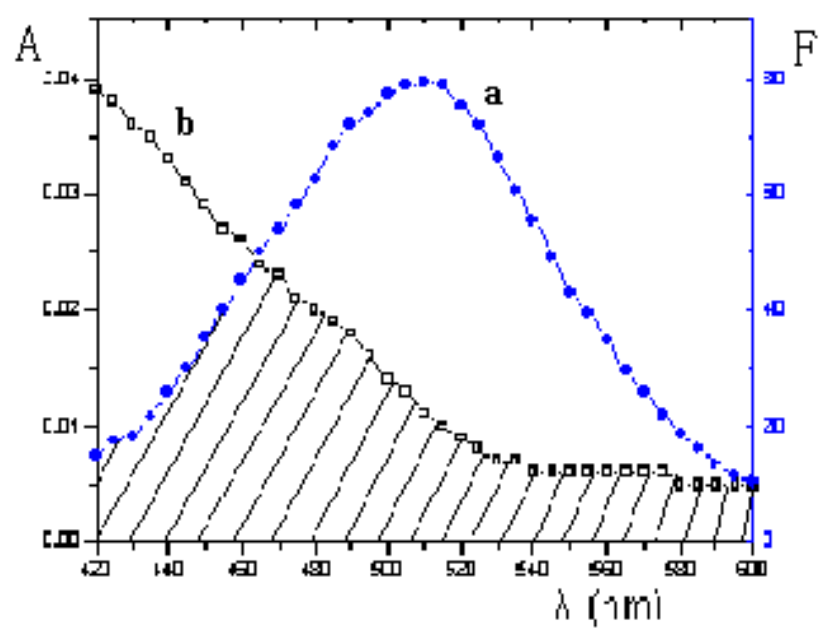

Figure 4. The overlap of the fluorescence emission spectra of $\operatorname{ENX(a)~with~the~absorption~spectra~(b)~}$ of BR.

\section{Acknowledgements}

The author wishes to express appreciation to Shandong province education department (project J13LD52), Weifang technology bureau (project 201301073) and Weifang Medical University domestic visiting scholar project for the financial support of this work.

\section{References}

[1] Fung YS, Sun DX, Yeung CY, Capillary electrophoresis for determination of free and albumin-bound bilirubin and the investigation of drug interaction with bilirubin-bound albumin. Electrophoresis, 21(2), pp. 403-410, 2000.

[2] Kazmierczak SC, Robertson AF, Catrou PG, Briley BL, Gourley GR. Direct Spectrophotometric Method for Measurement of Bilirubin in Newborns: Comparison with HPLC and an Automated Diazo Method. Clin Chem , 48(7), pp. 1096-1097, 2002.

[3] Zelenka J, Lenicek M, Muchova L, Jirsa M, Kudla M, Balaz P, Zadinova M, Ostrow JD, Wong RJ, Vitek L. Highly sensitive method for quantitative determination of bilirubin in biological fluids and tissues. J Chromatogr B, 867(1), pp. 37-42, 2008

[4] Liu JW, Zhou XM, Zhang MG. Chin J Chromatogr 1998;16:369. 10. Nie Z, Fung YS. Microchip capillary electrophoresis for frontal analysis of free bilirubin and study of its interaction with human serum albumin. Electrophoresis, 29(9), pp. 1924-1931, 2008.

[5] Andreu Y, Galban J, de Marcos S, Castillo JR. Determination of directbilirubin by a fluorimetric-enzymatic method based on bilirubin oxidase. Fresenius J Anal Chem, 368(5), pp. 516-521, 2000.

[6] Yuan JL, Wang GL, Majima K, Matsumoto K. Synthesis of a terbium fluorescent chelate and its application to time-resolved fluoroimmunoassay. Anal Chem, 73(8), pp. 1869-1876, 2001.

[7] Lu C, Lin JM, Huie CW. Determination of total bilirubin in human serum by chemiluminescence from the reaction of bilirubin and peroxynitrite. Talanta, 63, pp. 333-337, 2004.

[8] Lu C, Song G, Lin JM, Huie CW. Enhancement in sample preconcentration by the on-line incorporation of cloud point extraction to flow injection analysis inside the chemiluminescence cell and the determination of total serum bilirubin. Anal Chim Acta, 590, pp. 159-65, 2007.

[9] Lee HS, Karim MM, Alam SM, Lee SH. Quantitative determination of bilirubin by inhibition of chemiluminescence from lucigenin. Luminescence, 22, pp. 331-337, 2007.

[10] Jiang CQ, Wang T. Study of the interactions between tetracycline analogues and lysozyme. Bioorgan Med Chem, 12, pp. 2043-2047, 2004. 
[11] Jiang CQ, Gao MX,He JX. Study of the interaction between terazosin and serum albumin synchronous fl uorescence determination of terazosin. Anal Chim Acta, 452, pp. 185-189, 2002. 